\title{
Implementation science approaches to family planning and reproductive health: Experiential learning and sharing for implementers, policy-makers, researchers, and advocates
}

\author{
Laura Reichenbach \\ Population Council \\ Carolyn Rodehau \\ Population Council \\ Emily Peca \\ John Stanback
}

Follow this and additional works at: https://knowledgecommons.popcouncil.org/departments_sbsr-rh

Part of the Demography, Population, and Ecology Commons, Family, Life Course, and Society Commons, and the International Public Health Commons How does access to this work benefit you? Let us know!

\section{Recommended Citation}

Reichenbach, Laura, Carolyn Rodehau, Emily Peca, and John Stanback. 2016. "Implementation science approaches to family planning and reproductive health: Experiential learning and sharing for implementers, policy-makers, researchers, and advocates," Meeting report. Washington, DC: Population Council, The Evidence Project. 


\section{The Evidence Project}

Population Council

4301 Connecticut Avenue, NW, Suite 280

Washington, DC 20008 USA

tel +12022379400

evidenceproject.popcouncil.org

The Evidence Project is made possible by the generous support of the American people through the United States Agency for International Development (USAID) under the terms of cooperative agreement no. AID-OAA-A-13-00087. The contents of this document are the sole responsibility of the Evidence Project and Population Council and do not necessarily reflect the views of USAID or the United States Government.

\section{Evidence}

The Evidence Project uses implementation science-the strategic generation, translation, and use of evidence - to strengthen and scale up family planning and reproductive health programs to reduce unintended pregnancies worldwide. The

Evidence Project is led by the Population Council in partnership with INDEPTH Network, International Planned Parenthood Federation, PATH, Population Reference Bureau, and a University Research Network.

Published in June 2016.

Suggested citation: Reichenbach, Laura, Carolyn Rodehau, Emily Peca, and John Stanback. 2016. "Implementation Science Approaches to Family Planning and Reproductive Health: Experiential Learning and Sharing for Implementers, Policy-makers, Researchers and Advocates," Meeting Report. Washington, DC: Population Council, The Evidence Project.

Photo credit on cover page Ashish Bajracharya, 2016.

C) 2016 The Population Council, Inc. 


\section{Contents}

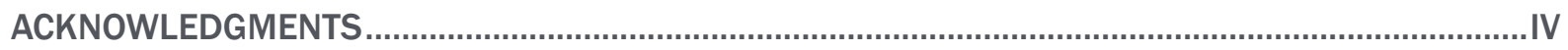

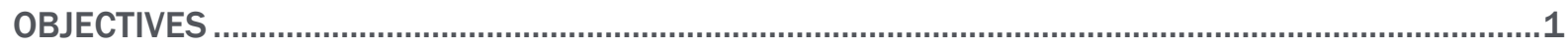

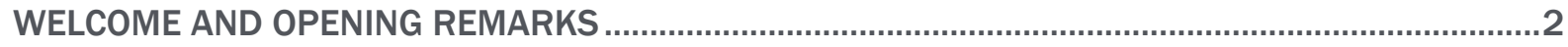

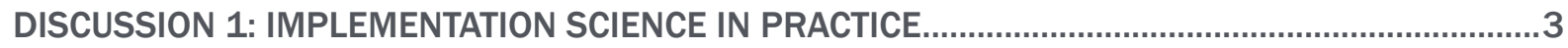

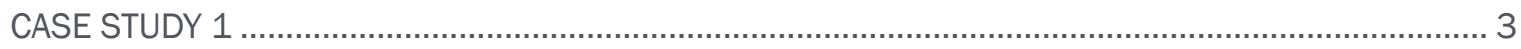

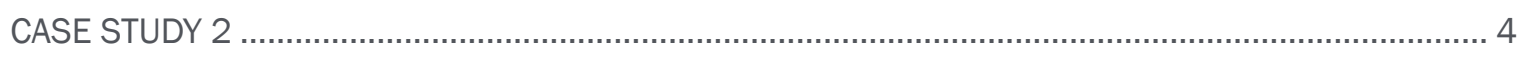

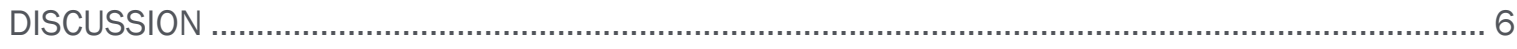

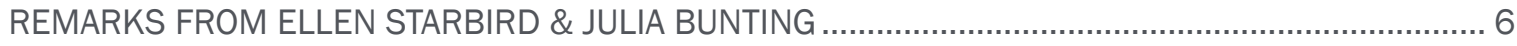

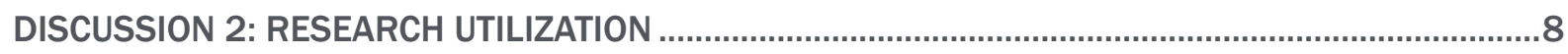

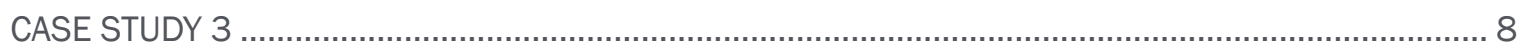

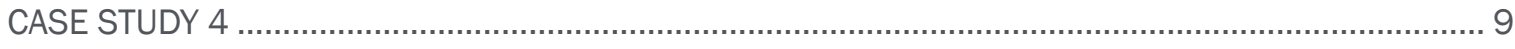

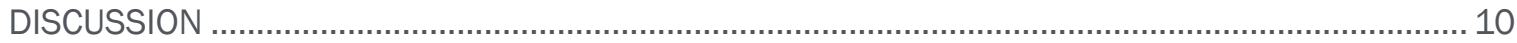

DISCUSSION 3: CURRENT AND FUTURE IS CHALLENGES AND OPPORTUNITIES ........................ 11

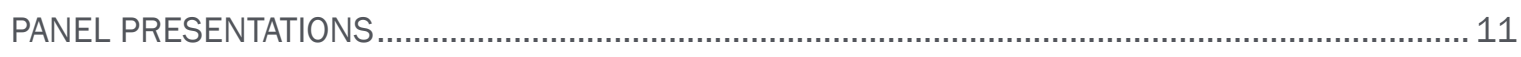

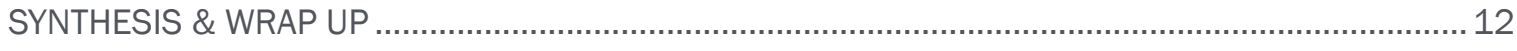

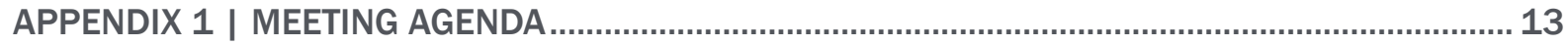

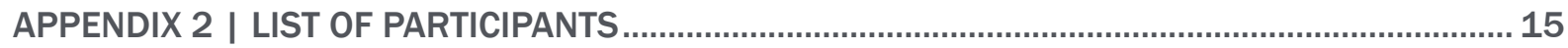

APPENDIX 3 | DEFINITIONS OF IMPLEMENTATION SCIENCE .....................................................17 


\section{Acknowledgments}

This workshop was funded by the United States Agency for International Development (USAID) through the Evidence Project, in collaboration with the TRAction Project. The organizing committee included: Marie Donaldson, Emily Peca and Sarah Weber (TRAction Project); John Stanback (FHI 360); Supriya Madhavan (USAID); and Laura Reichenbach (Population Council, Evidence Project). We also thank the speakers and moderators: Julia Bunting, Sarah Burns, Karen Hardee, Supriya Madhavan, Shawn Malarcher, Alison Marshall, Susan Newcomer, Emily Peca, Laura Reichenbach, Jim Sherry, John Stanback, Ellen Starbird, Petrus Steyn, and John Townsend. 


\section{Objectives}

This interactive half-day session provided participants with practical examples of how implementation science (IS) can inform programming and policies related to family planning and reproductive health. Presentations, case studies, and group discussions sought to address the following questions:

1. What are the benefits and challenges or limitations of an IS approach to FP/RH programming?

2. What is the relationship between evidence and advocacy?

3. How can evidence be best utilized to inform the scale up of programming and best practices?

4. How can we engage stakeholders and build institutional capacity to leverage IS approaches?

See Appendix 1 for the agenda of the meeting and Appendix 2 for a list of participants. 


\section{Welcome and Opening Remarks}

John Townsend from the Population Council provided the opening welcome to the participants. He set the tone for the day's agenda by reviewing the objectives for the pre-conference workshop.

Laura Reichenbach from the Evidence Project followed with opening remarks on how to find common ground in the field of IS based on practical experiences and case studies. Laura shared distinct definitions of IS from several perspectives (NIH, USAID, PEPFAR, Johns Hopkins University; see Appendix 3) and then highlighted three aspects that are common to all of them:

1. It is scientific/systematic in its approach

2. It is intended to improve delivery of health through a focus on policy, practice, programs or individual behaviors

3. It is focused on translation of results into utilization

Laura talked about the need to understand the rationale behind IS (closing the "know-do" gap, transferring knowledge from controlled settings into real-world policies and programs, and understanding the complexity of implementation) and underscored the urgency of IS (how do we ensure the adoption of policies and

"While there are multiple terms for implementation science representing different institutional perspectives, they share several similarities that foster a common understanding of implementation science"

\section{-Laura Reichenbach}

practices that are backed by evidence?).

Laura also spoke about what is unique to implementation science: it is trans-disciplinary, iterative and collaborative, informs decision-making, includes continuous learning and adaptation, and focuses on process-related outcomes such as feasibility and adoption. She also raised several challenges, including the methodological complexities of implementation research and how to rigorously document contextual factors with respect to the implementation of the intervention. 


\section{Discussion 1: Implementation Science in Practice}

The first discussion included two case study presentations on practical experiences conducting implementation science research. This discussion was moderated by Supriya Madhavan of USAID and included presentations from John Stanback of FHI 360 and Emily Peca of the TRAction Project, and discussant remarks from Susan Newcomer of the NIH. Supriya introduced this discussion by emphasizing USAID's commitment to IS and the timeliness of this conversation around a practical approach to IS. She explained that the two case studies presented in this session were selected to demonstrate how to do implementation science. See evidenceproject.popcouncil.org/resource/implementation-science-approaches-to-FP-and-RH/ for presentations.

\section{CASE STUDY 1}

\section{The Power of IS: Example of Task Shifting and Family Planning Experience from the PROGRESS Project}

John Stanback of FHI 360 presented the story of community-based access to injectables (CBA2I) under the USAID-funded PROGRESS Project, through the lens of implementation science. John started his remarks with background on CBA2I. Traditionally, injectable contraceptives are provided in a clinic or health facility setting. CBA2I is a model which extends these services into the communities where the clients live. Thus, the CBA2I model means training these community health workers to also offer injectable contraceptives.

John explained the PROGRESS Project's reason for focusing on injectables (high use, demand, safety, and availability) and a community-based approach (expands access, evidence-based and replicable model,

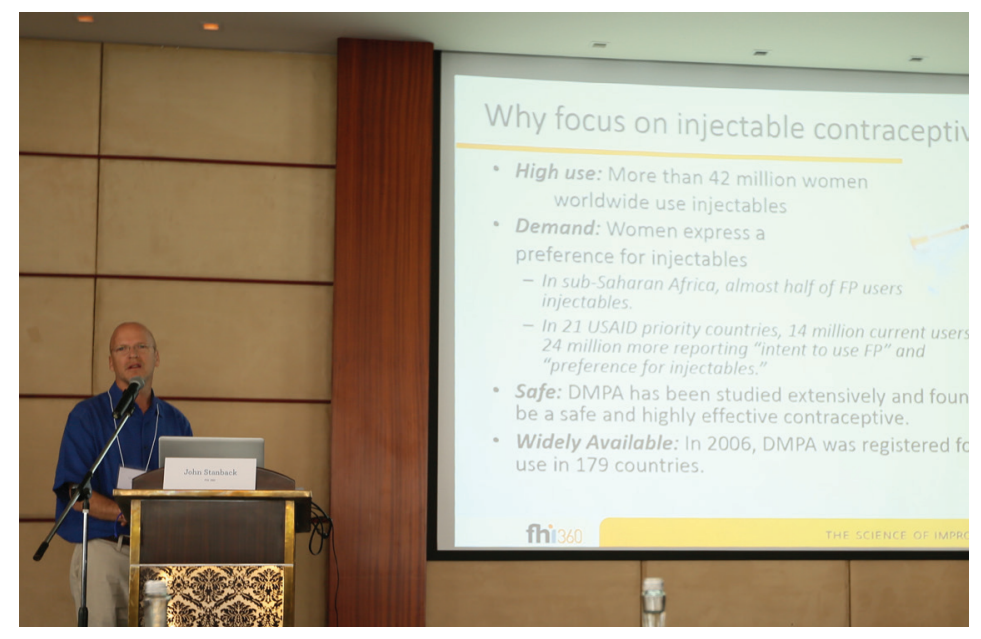
and can alleviate health worker shortages).

He also emphasized that this is not a new concept and went on to describe some of the initial work that took place 40-plus years ago in Bangladesh and other early efforts around task shifting regarding injectables.

John raised several implementation challenges encountered while conducting this research:

- Weak infrastructure and logistics

- Politics (resistance by medical professional communities)

- Reluctance of conservative Ministries of Health

- Concerns over safety

- Doubts about the ability of Community Health Workers (CHWs) to screen and counsel correctly

- Questions about the acceptability of CHWs offering this new service 
John then discussed specifics relating to the "how to" of implementation science. As a backdrop to this, he provided FHI 360's draft criteria for determining what constitutes implementation research:

- Deals with studying, as opposed to conducting, implementation

- Evaluates the implementation of an evidence-based intervention

- Produces generalizable results

- Examines intervention "fidelity"

- Includes pilot studies when

- Testing the feasibility and planning of a complex intervention

- Little or no evidence exists on a given topic, and if the risk from a larger study is too great

John also provided examples from several countries of CBA2I along the implementation research "arc": feasibility (Madagascar 2006 pilot), acceptability (Zambia 2009-2011), adoption (Nigeria 2009-2010), appropriateness (Senegal 2011-2013), fidelity (Uganda 2004-2005), cost (Zambia), coverage (Kenya 2009-2010), and sustainability (Uganda). John said that the arc highlights the importance of incremental change and impact. John highlighted Uganda as a success story where progress has been made and momentum is building, but there is still much farther to go. John also highlighted the challenges within IS study designs, where often the research does not include a comparison group or counter-factual.

\section{FIGURE 1 | ARC OF IMPLEMENTATION SCIENCE}

Adapted from Peters DH, Tran N, Adam T, Ghaffar A. Implementation research in health: A practical guide. Alliance for Health Policy and Systems Research, World Health Organization, 2013.

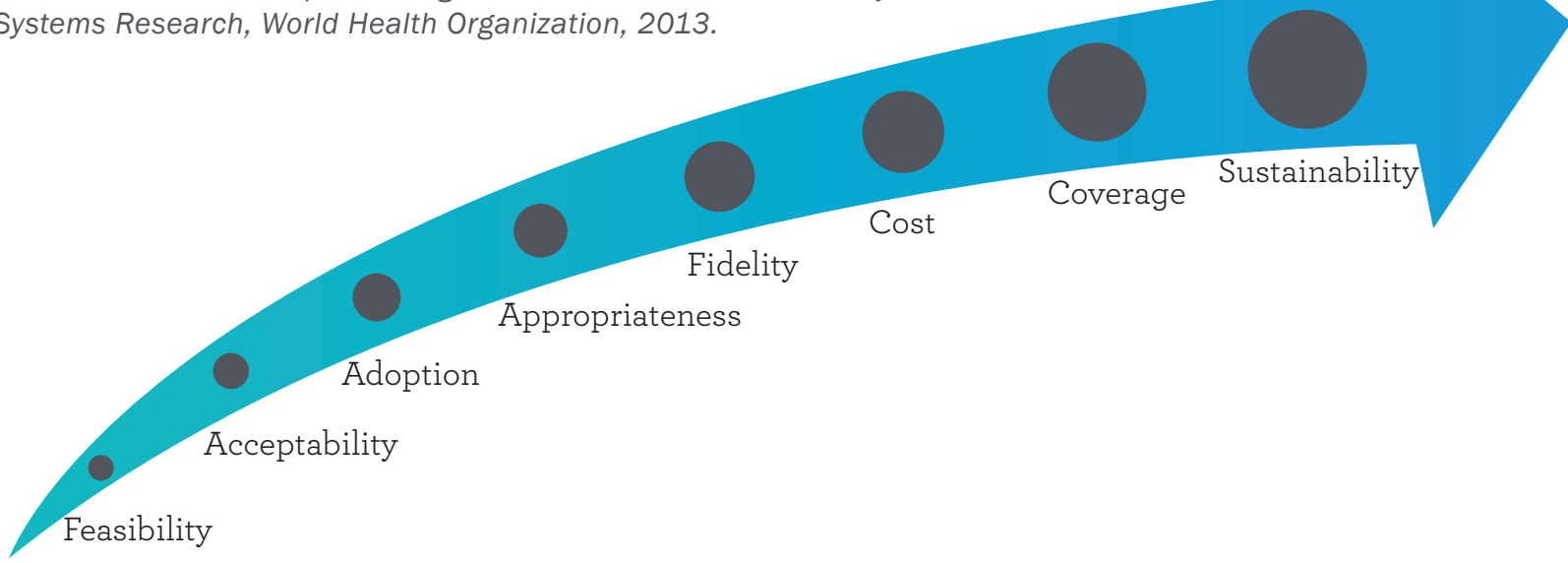

\section{CASE STUDY 2}

\section{Respectful Maternity Care (RMC), the Relationship between Evidence and Advocacy: An Evolving Story}

Emily Peca of the TRAction Project discussed the interplay between evidence and advocacy within efforts to address respectful maternity care (RMC). Emily explained that the occurrence of disrespect and abuse during childbirth was widely known based on anecdotal reporting, but had not been named or defined. This lack of terminology and definition sparked recent investments in work related to disrespect and abuse during facility delivery and in RMC. Emily went on to present a timeline of this work, starting with the initial landscape analysis conducted by Bowser and Hill (2010) that provided the first naming and framing of the issue. 
This early typology defined disrespect and abuse along the following seven domains: 1) Non-dignified care; 2) Abandonment/neglect; 3) Physical Abuse; 4) Non-confidential care; 5) Discrimination; 6) Non-consented care; and 7) Detention in health facilities for failure to pay.

Efforts to create an evidence base by developing measurement tools and strategies to improve quality through RMC followed. Emily highlighted a unique feature to this implementation research: while research was un-

"There was a perception that

maternal mortality and morbidity

were most urgent, and biomedical

approaches were focused on. What

shifted the discussion was this broader

narrative about QoC and that women's

experiences need to be balanced in

provision of care."

-Emily Peca dertaken to measure RMC in several settings, parallel advocacy efforts were led by civil society organizations which resulted in interest at the global level, and led to the WHO global technical consultation on Disrespect and Abuse Related to Maternity Care in November 2013. Emily's presentation of the timeline culminated with WHO's release of a joint statement on respectful maternity care in 2014 and how the WHO's new quality of care framework seeks to incorporate patient experience of care linked to quality and health outcomes. Within just one year, WHO renamed the issue to "mistreatment."

Regarding the IS research agenda, Emily discussed the challenges in teasing out which aspects of RMC interventions have been effective, partially due to a lack of agreed upon definition of and measures for RMC. She highlighted that this is a nascent field of study and that more IS research is needed on promising approaches.

Emily wrapped up the discussion with a series of lessons learned from the RMC experience:

- Launching evidence generation and advocacy in parallel from the start was critical.

- Community of practice facilitated interest at the global level and got the issue on WHO's agenda.

- "What to do" is complex and context specific.

- Going forward: must encourage documentation, evidence generation and sharing of evidence to grow the body of IS knowledge around RMC.

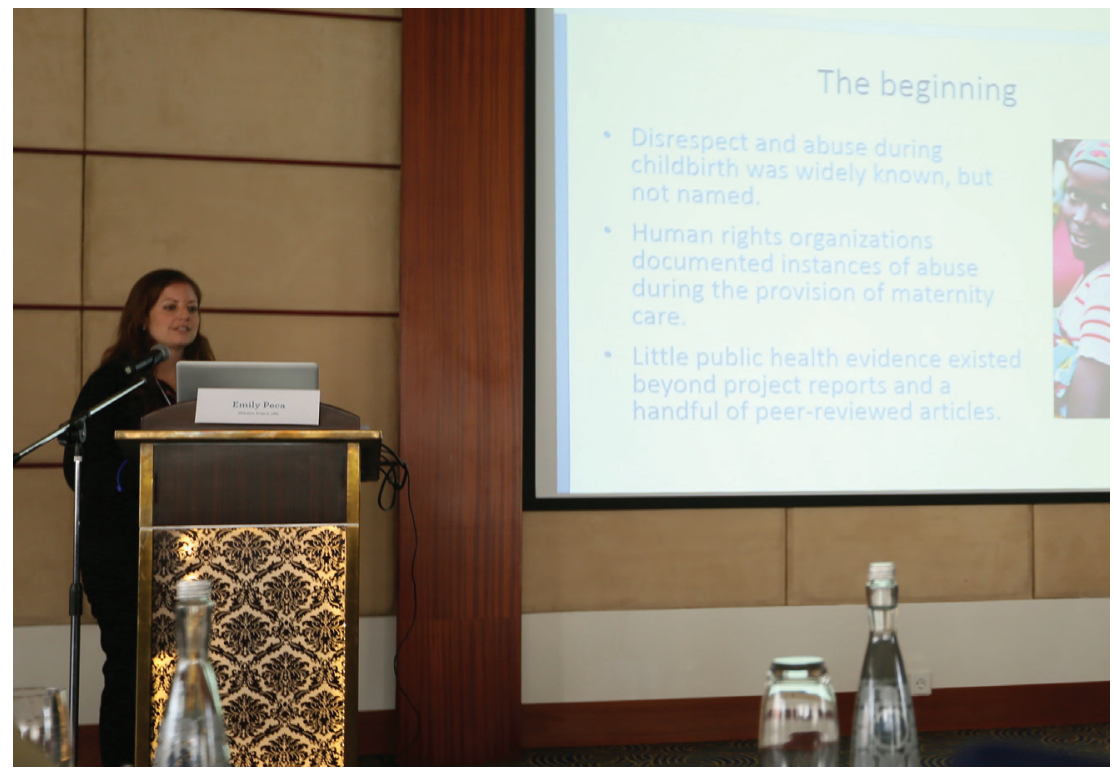




\section{DISCUSSION}

Susan Newcomer of NIH offered remarks after the presentation of the case studies, noting that IS is a rigorous evaluation methodology and that it is often a challenge to convince funders and reviewers to invest in research that does not employ the methods of randomized-controlled trials. On the other end of the spectrum, Susan mentioned the challenge of implementer "passion," which often presents itself with an implementer saying "I just know this works!" She commented that the RCT approach is not always ethical and ensuring fidelity is challenged by differing contexts. She noted and complimented the leadership USAID has shown in this area through sharing the documentation and the evidence for IS. Susan wished everyone strength and courage for work in family planning for the 50 years ahead.

Following Susan's remarks, a brief period for discussion followed. The group grappled with some of the following topics and questions:

- Do innovations really need to take this long to be understood and scaled up?

- How to respond to stated or perceived need for local data ("all women are different").

- Engaging local champions is critical.

- Respecting cultural and contextual differences is important.

- We must understand the power of language, as the example of RMC demonstrated, and the importance of naming and framing the issue to not only generate evidence but also to bolster advocacy around the issue.

- How can we strengthen our IS methodology so that we can meet the criteria for strong evidence?

- We cannot discount the importance of change agents in supporting behavior change in the diffusion of innovations.

- What more do we need to do to build local capacity to do IS and use evidence?

- We need to respect and study what does not work as much as what does.

\section{REMARKS FROM ELLEN STARBIRD \& JULIA BUNTING}

Following the tea break, remarks were provided by Ellen Starbird from USAID and Julia Bunting from the Population Council.

Ellen spoke about USAID's support for IS and how it is an important part of the office's portfolio, with funding levels around $\$ 9$ million annually. She stressed that evidence, science, and utilization are what have moved the field of family planning ahead, and the value of social science. Ellen went on to discuss the five focus areas for USAID's work on family planning: 1) method choice; 2) supply chains; 3) family planning workforce; 4) total market approach; and 5) social and behavior change communication. She also highlighted some of the challenges, particularly with getting what is being learned from studies into programs. Another challenge she noted for USAID is gaining a better understanding of the range of research that is being funded and avoiding duplication of research efforts. Her final statements stressed the need to use every channel to reach women in need - public sector, private sector, faith-based community, media, etc. — and the importance of learning what works and what doesn't work well by better documenting how we have modified a program when things did not go as expected.

Julia then spoke on behalf of the Population Council, a historical leader within operations research. Julia started by thanking USAID for their continued investment in IS and noting how critical this work is to taking 
programs to scale. She highlighted the need for researchers to present their work outside of peer-reviewed publications, and the importance of researchers knowing the audience that they are trying to reach with evidence and to understand what will speak to them. Both Julia and Ellen reminded us that policymakers are short on time and factor in many things beyond evidence when making decisions (politics, support, re-election, etc.). Julia also echoed Ellen's remarks on the need for research about what works and what doesn't work. She stressed that this is of critical importance given finite resources and that IS can play an important role in providing the evidence to show us what we should be funding.

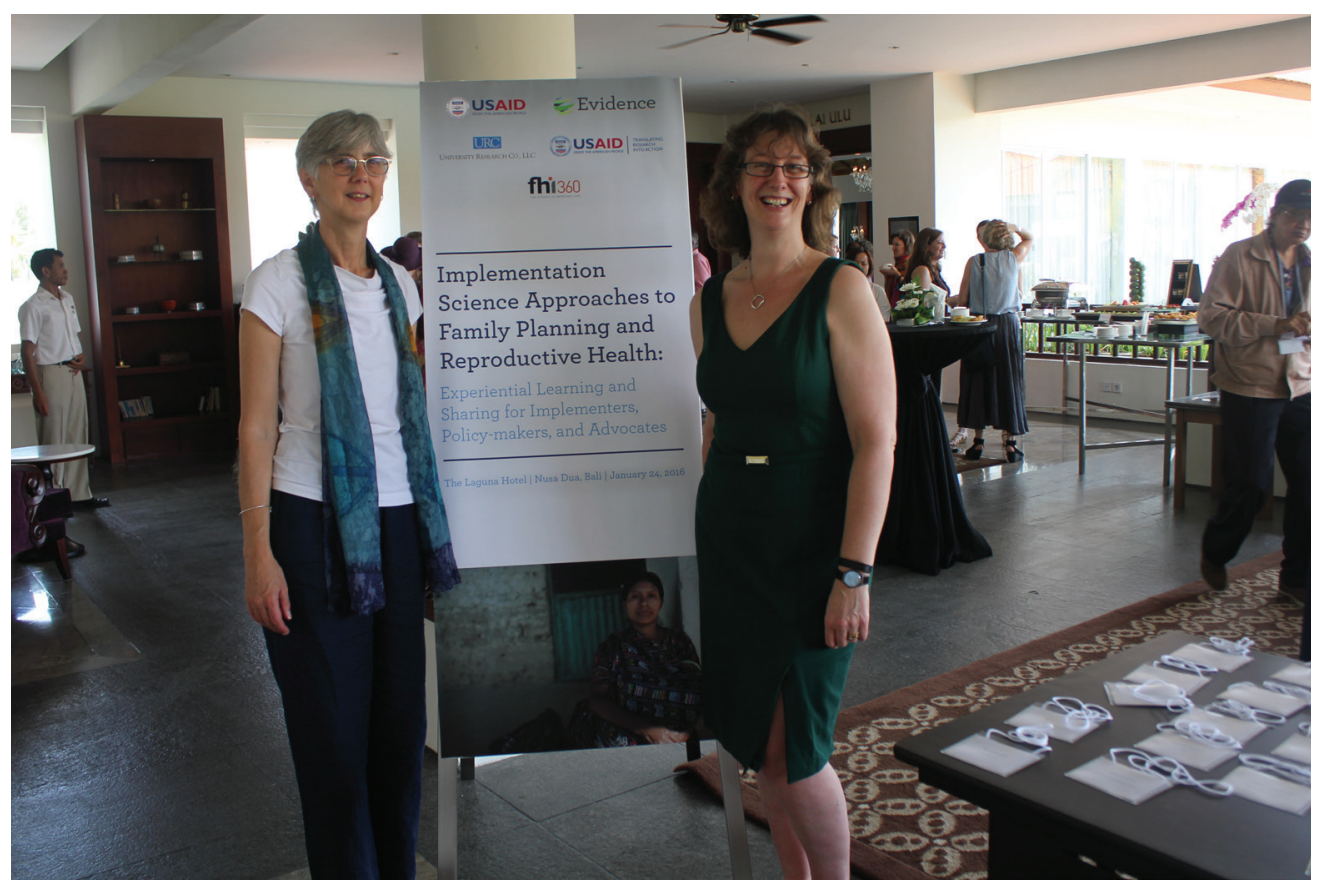




\section{Discussion 2: Research Utilization}

The second discussion included two case study presentations on what types of evidence are needed for decision-making and how we can ensure evidence is being used. This discussion was moderated by Jim Sherry of the TRAction Project and included presentations from Shawn Malarcher of USAID (on behalf of Ilene Speizer who was unable to attend the workshop) and Karen Hardee of the Evidence Project.

\section{CASE STUDY 3}

\section{Standards of Evidence to Inform Decision-making}

Shawn Malarcher described the efforts around documenting and sharing high impact practices in family planning (fphighimpactpractices.org), as well as the Croydon Meeting on Standards of Evidence (http://www.popcouncil.org/uploads/pdfs/2014STEPUP ConsultationStandards.pdf). She also highlighted several upcoming opportunities: the Bellagio Meeting - Consultation with consumers of evidence (http://evidenceproject.popcouncil.org/wp-content/ uploads/2016/05/5.3.16 Bellagio-Meeting-Report.pdf), new recommendations for GRADE (WHO), and new recommendations on how to measure normative change (IRH).

Shawn then discussed current changes regarding how we need to think about the strength of our evidence. Instead of asking "does it work?" we need to challenge ourselves to ask:

- Do we have enough evidence?

- Will this help us make better decisions?

- Will this make scale up more effective and more efficient?

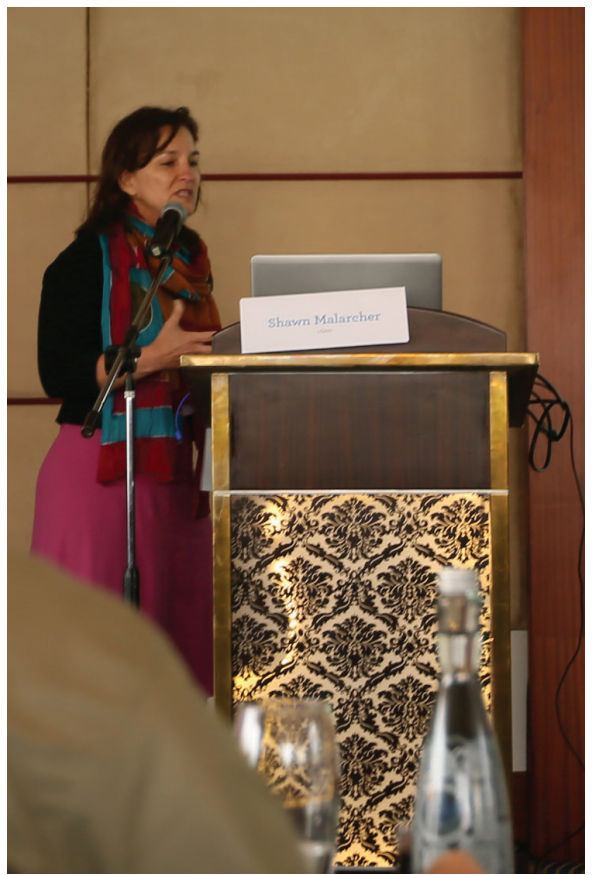

- How does it work?

- Who does it work for?

Shawn provided an example of triangulating client circumstances, client need, and program evidence in order to take a more realist review of the state of evidence, using the examples of school-based health centers and sexuality education, mass media, and social marketing/pharmacy-based distribution of FP methods.

She also noted the following key observations:

- Recommendations from systematic reviews are not always clearly communicated for application by program managers.

- Health systems and social science research benefit from nuanced recommendations.

- A theory-based review allows for flexibility in the review process.

- Incorporating context and needs of beneficiaries can better focus recommendations.

- Partnerships are key.

Shawn concluded with a proverb, "If you want to go quickly, go alone. If you want to go far, go together." 


\section{CASE STUDY 4}

\section{The Evidence that Evidence is Used: IS Approaches and Adaptations for Research Utilization - The Example of Standard Days Method (SDM)}

Karen Hardee of the Evidence Project opened her presentation acknowledging the growing attention that "evidence-based practices" are receiving in the field of family planning and reproductive health. Karen discussed where this evidence base comes from: biomedical contraceptive development, National Surveys (WFS, CPS, DHS), Operations Research, Implementation Research, and monitoring and evaluation data. She also highlighted the large number of family planning projects that have emphasized "getting evidence used": for example, the Data for Decision-making Project, E2A Project, MEASURE Evaluation, the Evidence Project, Advance Family Planning (AFP), IBP, and HIP. However, there has been little research into what decision-makers consider as "evidence" and how such evidence factors into their decision-making.

${ }^{6}$ There is surprisingly scant research on whether and how evidence is used in decision-making for FP/RH policies, programs and practices, despite a growing literature on research utilization, also known as knowledge translation, among other names, in global health"

Karen then focused her discussion on -Karen Hardee two recent Working Papers produced by the Evidence Project (http://evidenceproject.popcouncil.org/wp-content/uploads/2015/09/Expanding-the-Role-of-Evidence-in-Decisionmaking.pdf and http:// evidenceproject.popcouncil.org/wp-content/ uploads/2015/09/Role-of-Evidence-Working-Paper.pdf) that examine what we mean by "evidence" and what evidence there is that evidence is used in decision-making. This work looked at how researchers define evidence (i.e. research studies) and how decision-makers define evidence (i.e. research studies, but also M\&E data, program reports, policy documents, community input and professional experience). She also described the conceptual framework that the project is using to understand the role of evidence, particularly scientific evidence, in decision-making (based on Cookson, 2005).

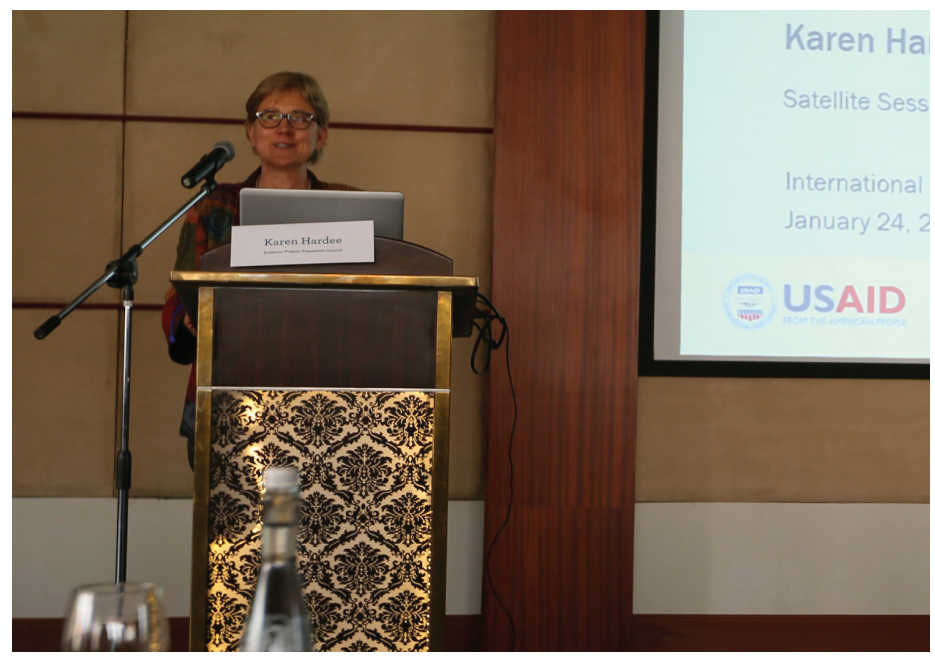

Karen discussed other factors that influence decision-making related to $\mathrm{FP} / \mathrm{RH}$ including:

- Political sensitivities (e.g. adolescent reproductive health)

- Turf battles (e.g. task shifting)

- Activist blockage (e.g. Depo-Provera in India)

- Era of HIV/AIDS (1990s)

- Modern vs. traditional methods (e.g. Standard Days Method - a modern method that some refuse to acknowledge as such) 
She provided an example using the Standard Days Method (SDM), which until recently was considered a traditional method. Karen described the continuum of studies conducted (including proof of concept, pilot introductions and efficacy trials, and impact studies) that, over a 12-year period, provided evidence on research, introduction and scale up of the Standard Days Method. One of the results was that SDM was listed as a modern method in the DHS.

Karen concluded her presentation with a discussion on when decision-makers actually use evidence in their decision-making process and what may influence decision-makers' use of evidence:

- Individuals value evidence, but structural issues intervene.

- Evidence that supports existing beliefs is more likely to be used.

- Evidence that goes against existing programming can be threatening.

- Evidence on problems easier to use than evidence on solutions.

- Lack of evidence for complex decisions - "wicked problems."

- Local evidence can be especially important for decision-makers.

- Donor priorities can influence what evidence is considered, and donors tend to rely on global data.

- Evidence is generally not the deciding factor in decision-making.

She stressed that policymakers want local data, which is a challenge for researchers to address.

\section{DISCUSSION}

The presentations were followed by an interactive discussion that addressed the following topics:

- Again, the importance of the power of language. Researchers need to know their audience and what they understand in terms of the language that is used. As an example of this, Susan Newcomer made the plea to reframe "unmet need" as "frustrated demand."

- How do we address the disappointing conclusion that most research calls for more research?

- "Publish and then it will be adopted" is not the way it happens in real life.

- How can we better understand the role of individual researchers as agents of change, with varying degrees of effectiveness at translating findings into actions?

- The need for healthy debate within $\mathrm{FP} / \mathrm{RH}$ and how we need to hold each other accountable to high standards based on facts and evidence.

- What is the best strategy for involving policymakers in research, which has both benefits (faster/ensured translation into policies) and challenges (high level of investment in outcome can lead to disregard of negative or null effects).

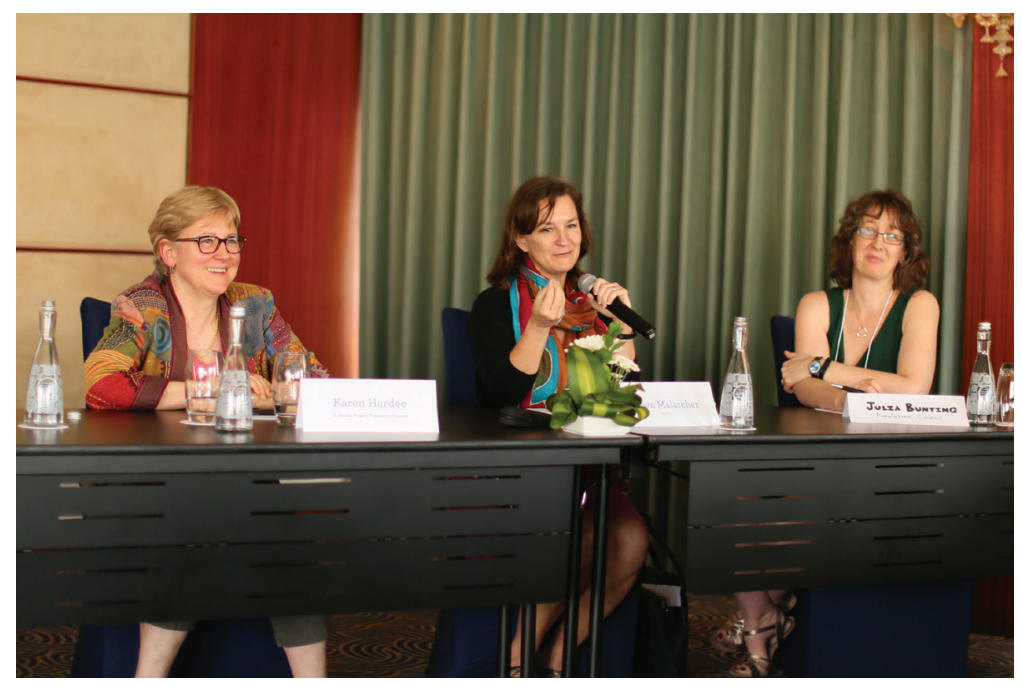




\section{Discussion 3: Current and Future IS Challenges and Opportunities}

The third discussion featured a panel moderated by John Townsend from the Population Council, with Sarah Burns from Pathfinder and the IBP Initiative, Alison Marshall from IPFF, and Petrus Steyn from WHO. The panel was followed by a moderated discussion.

\section{PANEL PRESENTATIONS}

\section{The State of IS in IBP Member Organizations}

Sarah talked about the IBP Initiative and how it manages the documentation and dissemination of knowledge among its member organizations. In July 2015, the IBP Initiative's Knowledge Management Task Team released a report on the State of Implementation Science in IBP Member Organizations. Results from this report were primarily gathered through a survey, which was sent to all IBP members. Twenty-seven organizations/projects responded to the survey. Survey questions explored how IS is defined, the usefulness of IS, and current IS activities of IBP member organizations.

Two ways of defining IS emerged: 1) IS is defined as researchers conducting research to influence policy and future programs, and 2) IS is defined as implementers doing IS to adapt a project in real time. Ultimately, the goal of IS in both cases is to improve program implementation. Sarah shared that the survey found the usefulness of IS was related to its heavy emphasis on data, usefulness to programs, and external sharing. She also highlighted that a majority of respondents said that they systematically used external research.

Another area the survey focused on was donor priorities and funding. Sarah indicated that survey respondents felt that donors either fund research or implementation, but not a combination of both. Respondents also expressed challenges measuring the success of IS.

\section{Programmatic Perspectives and Reflections}

Alison called for more partnership between the research and advocacy communities. She stressed that IS researchers and advocates are in this together and that when these two groups work together, it can make a huge difference. She also emphasized that research is not the end product, but rather that policy change is the final goal, and achieving this requires successful collaboration between researchers and advocates.

Alison also discussed the role of advocates as the translators of evidence, highlighting that decision-makers are risk-averse and need data on cost in order to make better decisions. She stressed that advocates must convince policymakers that the pain of changing is less than the pain of staying the same, and the importance of being able to respond to policymakers' desire for local research (i.e. "this won't work for our women").

Alison also raised two challenges: 1) how can we really show A leads to B (which is context specific) and 2) the lack of research on advocacy and accountability - how can we do these things better to change policy?

\section{WHO Perspectives and Reflections}

Petrus discussed the importance that WHO has placed on rigorous research as well as the challenge of taking 
clinical guidelines and using them in the real world. He also talked about a forthcoming review from the WHO that looks at values and preferences for different types of evidence within FP/RH.

Petrus also discussed the opportunities to use IS for real-time performance review and scale up. He emphasized the importance of the way interventions are written-up and shared, because whenever health and behavior change is involved, the design will also be complex. He also stressed the importance of getting key stakeholders involved from the start/inception of the research.

One issue Petrus raised that had not come up in earlier discussions was the importance of ensuring ethically sound behavior when carrying out IS and the importance of having clear requirements for ethical review boards to consider when reviewing IS.

\section{SYNTHESIS \& WRAP UP}

John Townsend wrapped up the workshop noting two important topics the workshop did not have time to discuss: 1) ethics and 2) rights. After providing a brief summary of the day, he closed the session by stressing that partnership is key for scale up.

The presentations and rich discussions at the meeting highlighted several areas that require further consideration and attention in order to move the field of implementation science forward. Some of these include:

- Better documentation of the context in which interventions are implemented in order to better understand implementation barriers and facilitators as well as to inform replication of interventions to different settings and their scale up. This calls for careful documentation of examples of IS in FP/ RH shared through peer-reviewed literature and other avenues in order to make them widely available and accessible.

- Clear examples of what is successful implementation science and how it is measured (i.e., feasibility, sustainability, scale up). Engaging donors and funders in the development and refinement of these measures may help to identify new investment opportunities in implementation science.

- Development of the capacity building agenda for IS at different levels (e.g. local researchers, national policymakers, global and national implementers, advocates) will strengthen the influence of implementation science.

- Finding opportunities to strengthen partnership between the research and advocacy communities to generate additional avenues to ensure evidence utilization.

- Determining how best we can use IS to get better costing data so that we can publicize "best buys" within $\mathrm{FP} / \mathrm{RH}$.

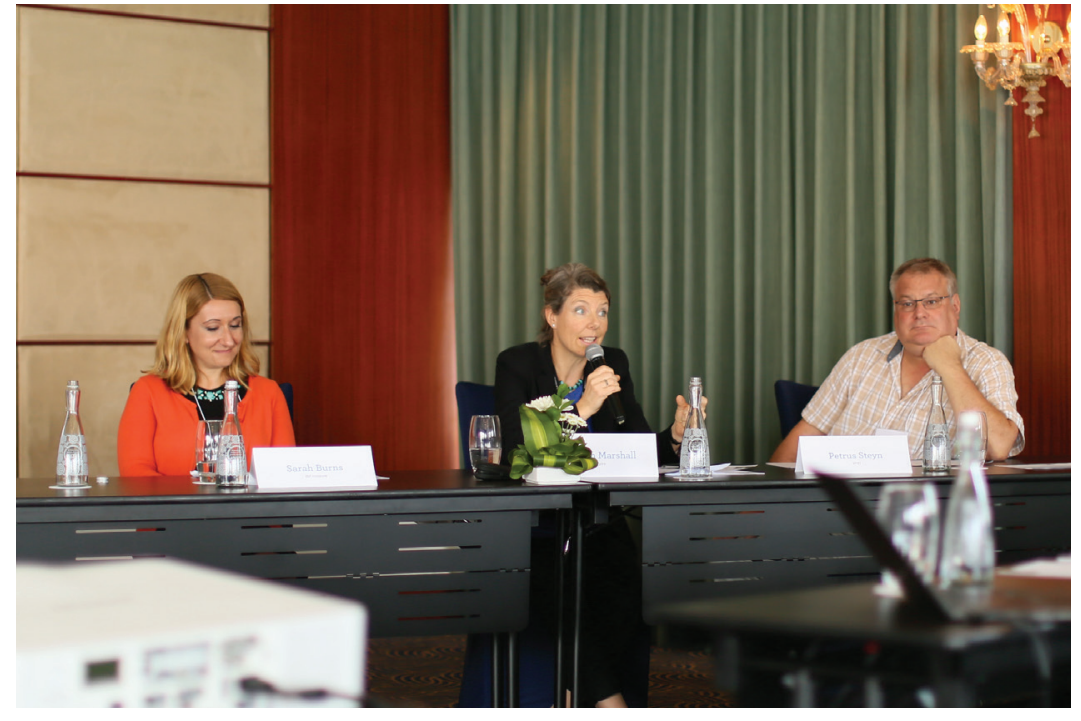




\title{
Appendix 1 | Meeting Agenda
}

\author{
8:30 - 9:00 ARRIVAL, REGISTRATION \& BREAKFAST \\ 9:00 - 9:15 WELCOME, OVERVIEW, AND OBJECTIVES OF SESSION \\ John Townsend \\ Population Council \\ 9:15 - 9:30 OPENING: FINDING COMMON GROUND \& PERSPECTIVES \\ Laura Reichenbach \\ The Evidence Project \\ What sets IS apart? What are the definitions and distinguishing factors of an \\ IS approach?
}

\begin{tabular}{|c|c|c|c|}
\hline \multirow[t]{3}{*}{$9: 30-10: 30$} & \multicolumn{3}{|c|}{$\begin{array}{l}\text { DISCUSSION } 1 \\
\text { Implementation Science in Practice }\end{array}$} \\
\hline & \multicolumn{3}{|c|}{$\begin{array}{l}\text { The Power of IS: Example of Task Shifting and Family Planning, } \\
\text { Experience from the PROGRESS Project }\end{array}$} \\
\hline & \multicolumn{3}{|c|}{$\begin{array}{l}\text { Respectful Maternity Care (RMC), the Relationship Between } \\
\text { Evidence and Advocacy: An Evolving Story }\end{array}$} \\
\hline \multicolumn{4}{|c|}{$\begin{array}{c}\text { What can we learn from examples of IS approaches to global health } \\
\text { programming and policy making? }\end{array}$} \\
\hline MODERATOR & & PRESENTERS & DISCUSSANT \\
\hline \multicolumn{2}{|c|}{ Supriya Madhaven } & John Stanback & Susan Newcomer \\
\hline \multirow[t]{3}{*}{ USAID } & & FHI36o & National Institutes for Health \\
\hline & & Emily Peca & \\
\hline & & TRAction Project & \\
\hline $10: 30-11: 00$ & \multicolumn{3}{|c|}{ TEA AND COFFEE BREAK } \\
\hline \multirow[t]{5}{*}{ 11:00 - 11:10 } & \multicolumn{3}{|c|}{ REMARKS } \\
\hline & \multicolumn{3}{|c|}{ Ellen Starbird } \\
\hline & \multicolumn{3}{|c|}{ USAID } \\
\hline & \multicolumn{3}{|c|}{ Julia Bunting } \\
\hline & \multicolumn{3}{|c|}{ Population Council } \\
\hline
\end{tabular}




\begin{tabular}{|c|c|c|}
\hline \multirow[t]{3}{*}{ 11:10 - 12:00 } & \multicolumn{2}{|l|}{$\begin{array}{l}\text { DISCUSSION } 2 \\
\text { Research Utilization }\end{array}$} \\
\hline & \multicolumn{2}{|c|}{$\begin{array}{l}\text { CASE STUDY } \mathbf{3} \\
\text { Standards of Evidence to Inform Decision-making }\end{array}$} \\
\hline & \multicolumn{2}{|c|}{$\begin{array}{l}\text { The Evidence that Evidence is Used: IS Approaches and } \\
\text { Adaptations for Research Utilization - The Example of Standard } \\
\text { Days Method (SDM) }\end{array}$} \\
\hline \multicolumn{3}{|c|}{$\begin{array}{l}\text { What evidence is needed for decision-making and how can we ensure } \\
\text { evidence is used? }\end{array}$} \\
\hline MODERATOR & PRESENTERS & DISCUSSANT \\
\hline Jim Sherry & Ilene Speizer & Shawn Malarcher \\
\hline \multirow[t]{3}{*}{ TRAction Project } & UNC & USAID \\
\hline & \multicolumn{2}{|l|}{ Karen Hardee } \\
\hline & \multicolumn{2}{|c|}{ The Evidence Project } \\
\hline
\end{tabular}

\section{2:00 - 12:50 DISCUSSION 3}

Current and Future IS Challenges and Opportunities

\section{PANEL PRESENTATIONS}

The State of IS in IBP Member Organizations

Programmatic Perspectives and Reflections

WHO Perspectives and Reflections

How can we engage stakeholders and build institutional capacity to leverage IS approaches?

MODERATOR

John Townsend

Population Council
PANELISTS

Sarah Burns

IBP Initiative

Alison Marshall

IPPF

Petrus Steyn

$\mathrm{WHO}$

\section{$12: 50$ - 1:00 SYNTHESIS \& WRAP-UP \\ John Townsend \\ Population Council}

$1: 00-2: 00 \quad$ BUFFET LUNCH 


\section{Appendix 2 | List of Participants}

\begin{tabular}{|c|c|c|}
\hline NAME & ORGANIZATION & EMAIL ADDRESS \\
\hline Ashsh Bajracharya & Population Council & abajracharya@popcouncil.org \\
\hline Janine Barden-O'Fallen & MEASURE Evaluation & bardenof@email.unc.edu \\
\hline Reena Borwankar & FHI 360 & rborwank@fhi360.org \\
\hline Lindsay Breithaupt & Jhpiego & Lindsay.breithaupt@jhpiego.org \\
\hline Julia Bunting & Population Council & jbunting@popcouncil.org \\
\hline Sarah Burns & Pathfinder International & sburns@pathfinder.org \\
\hline Jacquelyn Caglia & $\begin{array}{l}\text { Harvard TH Chan School of } \\
\text { Public Health }\end{array}$ & jcaglia@hsph.harvard.edu \\
\hline Angela Coral & Rabin Martin & Angela.coral@rabinmartin.com \\
\hline Joanna Cordero & WHO & corderoj@who.int \\
\hline Jamaica Corker & University of Geneva & Jamaica.corker@unige.ch \\
\hline Yetuayet Demessie & EngenderHealth & yasfaw@engenderhealth.org \\
\hline Marie Donaldson & URC & mdonaldson@urc-chs.com \\
\hline Karen Hardee & Population Council & khardee@popcouncil.org \\
\hline Roy Jacobstein & Intrahelath & rjacobstein@intrahealth.org \\
\hline Anushka $\mathrm{Ka}$ & International Medical Corps & akalyanpur@internationalmedicalcorps.org \\
\hline Supriya Madhavan & USAID & smadhavan@usaid.gov \\
\hline Shawn Malarcher & USAID & smalarcher@usaid.gov \\
\hline Alison Marshall & IPPF & amarshall@ippf.org \\
\hline Tim Mastro & FHI 360 & tmastro@fhi360.org \\
\hline Misti McDowell & FHI 360 & mmcdowell@fhi360.org \\
\hline Shelly Megquier & PRB & smgegquier@prb.org \\
\hline Angela Nash-Mercado & Jhpiego & Angela.nash-merado@jhpiego.org \\
\hline Susan Newcomer & NIH & newcomes@mail.nih.gov \\
\hline Emily Peca & URC & epeca@urc-chs.com \\
\hline Chelsea Polis & Guttmacher Institute & cpolis@guttmacher.org \\
\hline Laura Raney & Jhpiego & laura.raney@jhpiego \\
\hline Laura Reichenbach & Population Council & lreichenbach@popcouncil.org \\
\hline Djarot Santoso & & djarotsantoso@yahoo.com \\
\hline Iqbal Shah & $\begin{array}{l}\text { Harvard TH Chan School of } \\
\text { Public Health }\end{array}$ & ishah@hsph.harvard.edu \\
\hline Caitlin Shannon & EngenderHealth & cshannon@engenderhealth.org \\
\hline Jim Sherry & URC/CUNY & jim.sherry@gmail.com \\
\hline Jennifer Smit & Match Resear & jsmit@matchresearch.co.za \\
\hline John Stanback & FHI 360 & jstanback@fhi360.org \\
\hline Ellen Starbird & USAID & estarbird@usaid.gov \\
\hline Petrus Steyn & WHO & steynp@who.int \\
\hline
\end{tabular}




\begin{tabular}{l|ll}
\multicolumn{1}{c}{ NAME } & \multicolumn{1}{c}{ ORGANIZATION } & \multicolumn{1}{c}{ EMAIL ADDRESS } \\
\hline John Townsend & Population Council & jtownsend@popcouncil.org \\
\hline Beverly Tucker & Male Contraceptive Initiative & beverly@malecontraceptive.org \\
\hline Rob Ubaidur & Population Council & urob@popcouncil.org \\
\hline $\begin{array}{l}\text { Tisna Veldhuijzen van } \\
\text { Zanten }\end{array}$ & URC & tveldhiujzen@urc-chs.com \\
\hline Elspeth Williams & Population Council & ewilliams@popcouncil.org
\end{tabular}




\section{Appendix 3 | Definitions of Implementation Science}

"Application of systematic learning, research and evaluation to improve health practice, policy and programs." -USAID, GH, n.d.

"Implementation science is the study of methods to promote the integration of research findings and evidence into healthcare policy and practice."

$-\mathrm{NIH} / \mathrm{FIC}$

"The study of methods to improve the uptake, implementation, and translation of research findings into routine and common practices."

$-P E P F A R$

"Effective IRDS involves using scientific methods to address the challenges of implementation and scaleup. IRDS draws upon the methods, tools, and approaches for: enhancing equity and efficiency, promoting a culture of evidence-informed learning, engaging stakeholders, and improving decisions on policies and programs to achieve better health outcomes. IRDS is a type of health policy and systems research that draws on many traditions and disciplines of research and practice. It builds on operations research, participatory action research, management science, quality improvement, implementation science, and impact evaluation.”

-Statement on IRDS

"Implementation research is the scientific inquiry into questions concerning implementation-the act of carrying an intention into effect, which in health research can be policies, programmes, or individual practices (collectively called interventions)."

-Peters Et Al. 2013. BMJ 


\section{The Evidence Project}

Population Council

4301 Connecticut Avenue, NW, Suite 280

Washington, DC 20008 USA

tel +12022379400

evidenceproject.popcouncil.org 